\title{
A THEORETICAL LOOK AT BICULTURALISM IN INTERCOUNTRY ADOPTION
}

\begin{abstract}
Intercountry adoption has been, and continues to be, a popular method of family formation worldwide, as well as a means of pro- viding homes for children who would otherwise remain parentless. The popularity of this social welfare practice suggests that countless families continue to face the challenges of raising children whose ethnicities derive from two different ethnic backgrounds. Yet, virtually no research exists on the development of a bicultural ethnic identity in intercountry adoption. Instead, research has focused on the importance of birth-culture socialisation, or the lack thereof. Faced with too little direct research on the subject, this paper synthesises and critically reviews literature from the ethnic socialisation, biracial, acculturation and adoption fields. The aim was two-fold: (1) extrapolate key elements of the literature that inform on the development of biculturalism in intercountry adoptions; and (2) identify gaps in the literature. Suggestions for future research and practice are made.
\end{abstract}

Key words:

Intercountry adoption

Transracial adoption

Ethnic socialisation

Biculturalism

Acculturation

Ethnic identity development

Scherman, R. (2010). A theoretical look at biculturalism in intercountry adoption. Journal of ethnic and cultural diversity in social work, 19(2), 127-142. 


\section{Introduction}

Intercountry adoption (ICA), in which children from one country are adopted into the homes of another, is a world-wide phenomenon that continues to be a popular method of forming or expanding families (Selman, Moretti, \& Brogi, 2009). While ICA began as a humanitarian response to children made parentless by war or poverty, for years now, ICA has been a means of providing children for otherwise childless couples (Altstein \& Simon, 1991). The vast majority of these international adoptions are also transracial. That is, they involve the adoption of children who are racially different from the (typically) white European adoptive parents. As such, the research into ICA, like that into transracial adoption (TRA), has frequently focused on the ethnic identity development of children, concluding that children whose parents provide birth-culture socialisation have better adjustment outcomes than those children whose parents emphasise dominant-culture socialiation (Brottveit, 1999; Carstens \& Juliá, 2000; Huh \& Reid, 2000; Irhammar \& Cederblad, 1999; Sætersdal \& Dalen, 2000). Yet, one question remains poorly answered: Is a bicultural identity (also referred to as biculturalism) achievable for children in transracial or intercountry adoptions?

While it may seem logical that a child born of one ethnic heritage, and raised within a family of a different ethnic background, will likely develop an ethnic self-identity that incorporates both cultures, very few researchers have sought to explicitly determine if children involved in ICA/TRA can, should or will development bicultural ethnic identities. Therefore, the aim of this paper is to offer a critical synthesis of the relevant fields of research-biracial, bicultural and acculturation studies-as seen first from within the ethnic socialisation literature, and then applied to the adoption context. Key findings, as well as weaknesses in the literature are highlighted throughout. The paper ends with a discusion of the gaps in our current knowledge, and suggestions for future research and practice. First, however, we begin with a look at the terminology associated with the topic of biculturalism, and the complications that arise with the inconsistent usage of important terms. 


\section{A problem with terminology}

After examining the ethnic socialisation literature, it is clear that there is a lack of consensus over the meaning of terms such as race, ethnicity and culture (Freundlich, 2000; Helms, 1990; Phinney, 1990; Rotheram \& Phinney, 1987; Thomas, 1986). Compounding the problem is the fact that the differences are often subtle. The term race, for instance, is most often found in the literature to denote and distinguish groups of people on the basis of physical appearance and biological characteristics (Freundlich, 2000; Thomas, 1986). By contrast, ethnicity is said to pertain to group classifications (Rotheram \& Phinney, 1987); a type of categorisation based on labelling (by self or other persons) that reflects membership in, a sense of belonging to, evaluation of, and identification with, that group (Caldwell-Colbert et al., 1998; Thomas, 1986). Ethnicity, according to Caldwell-Colbert et al. (1998), includes "feelings, thoughts, perceptions, expectations and actions of a group resulting from shared historical experiences" (p. 1). Race, on the other hand, is said to lack the behavioural, psychological or social implications associated with ethnicity (Helms, 1990). Yet, Caldwell-Colbert et al. (1998), posit that race does, in fact, have social meaning (both positive and negative), causing the two terms to overlap.

The American Psychological Association (APA, 2002) in its Guidelines on Multicultural Education, state that ethnicity is "the group mores and practices of one's culture of origin and the concomitant sense of belonging" (p. 2). An ethnic group, by extension, is any collection of people who consider themselves to be members, and sharing the common attributes, of that group (Rosenthal, 1987; Rotheram \& Phinney, 1987). The challenge is in agreeing on what makes up these common attributes. Finally, Phinney (1990) stresses that the group need not have "minority" status to be considered an ethnic group, despite the almost universal research focus on minority groups within the ethnic socialisation field.

Culture has been defined as "the system of shared ideas and meanings, explicit and implicit, which a people use to interpret the world and that serve to pattern their behaviour" (Halsall, 1995, p. 1). This definition overlaps somewhat with the APA's definition of ethnicity reported above. According to Thomas (1986), these shared 
characteristic patterns of behaviour are learned, rather than related to race or physiological characteristics of group membership. He also contends that culture, as a concept, is often ambiguous and problematic since within any group, there is no generally agreed upon list of what constitutes the culture of the group; and that which does constitute culture (language or customs, for example) is not always distinguishable from other cultural groups. Given the breadth of possible elements, it would be difficult to accurately identify that which comprises any particular culture.

\section{Ethnic identity}

While ethnicity, as described above, pertains to group categorisation, ethnic identity is said to refer to how one acquires the "group patterns" associated with that ethnic group (Rotheram \& Phinney, 1987, p. 13). According to Tajfel (1981), ethnic identity is the ethnic component of social identity; "that part of an individual's self-concept which derives from his knowledge of his membership of a social group (or groups) together with the value and emotional significance attached to that membership" (cited in Phinney, 1990, p. 500). Sometimes described in the literature as racial identity, as it often pertains to an understanding of one's racial group (Helms, 1990), ethnic identity is considered to be conceptually as well as functionally distinct from one's personal identity, which is defined as the "universal components of behaviour" such as selfesteem, self-worth, personality traits, etc. (Cross, 1987, p. 121), even though the two may mutually influence one another.

\section{Bicultural and biracial identity}

Within the ethnic socialisation literature, bicultural identity is simply an extension of ethnic identity, whereas one simultaneously identifies with two different ethnic groups (Aboud, 1987). Often referred to as biculturalism, it is defined as having knowledge of language, lifestyle characteristics and patterns of interpersonal behaviour of two distinct cultural groups (Thomas, 1986). It has also been described as the ability to function in two different cultures, by switching between two sets of norms, values and attitudes (Rotheram \& Phinney, 1987). Biracial, on the other hand, describes the person who is typically of mixed parentage, who simultaneously possesses the biological attributes of two different racial groups (Herring, 1995; Kich, 1992). 
According to Brown (1990), it is the mixed-race children who are the most likely to achieve biculturalism. "Due to their unique developmental history, mixed race children will typically possess more insight and sensitivity to both racial groups than single race children since they know firsthand what the racial identity of each implies" (p. 320). However, some researchers have argued that biracial children often lack access to one or another of their racial groups, and instead they are often forced to "choose" one over another (Herring, 1995; Williams, 1999). In that case, this author argues that the child would be biologically biracial, but not bicultural-a distinction all but absent from the literature. In other words, a child who is biologically both black and white (to use common U.S. vernacular), despite being raised by parents who represent both ethnic groups, may lack the socialisaion of one or the other of his/her ethnic backgrounds, necessary to achieve a bicultural ethnic identity.

Some researchers have questioned whether a child can, or even should, develop a bicultural identity (Katz, 1996; Thomas, 1986). Rotheram and Phinney (1987) have argued that it is not possible for children to have a bicultural self-identification; "they cannot simultaneously label themselves as belonging to two different groups", so instead, they refer to biculturalism as a type of bicultural competence (p. 24).

In defining what it means to be culturally competent, LaFromboise, Coleman and Gerton (1993) stated that:

an individual would have to possess a strong personal identity, have knowledge of and facility with the beliefs and values of the culture, display sensitivity to the affective processes of the culture, communicate clearly in the language of the given cultural group, perform socially sanctioned behaviour, maintain active social relations within the cultural group, and negotiate the institutional structures of that culture. (p. 396)

Summarising research on cultural competence in transracial adoptive parenting, outlined within a social work perspective, Vonk (2001) argues that cultural competence can only be achieved through an "active process of learning and practicing over time", 
(p. 248), as one gains the knowledge, attitudes and skills pertinent to the focal culture. Despite the differing contexts for viewing cultural competence, the above authors agree that cultural competence can be a challenge to achieve, even more so if one is not raised within a given culture, and particularly if one is aiming to achieve bicultural competence (LaFromboise et al., 1993). It has not, however, been suggested that bicultural competence is inherently unachievable (Aboud, 1987; LaFromboise et al., 1993; Rosenthal, 1987).

Despite the theoretical debate over the capacity to develop a bicultural ethnic identity, many researchers see it as a positive outcome, whereby the person's two cultures become "synthesised" (Rosenthal, 1987, p. 170). As such, being bicultural may have positive benefits for the individual, as the norms of both cultures are assimilated and available to use as needed, depending on the context. Rosenthal (1987) also believes that biculturalism permits the individual to select the features of the two cultures, allowing a "psychological flexibility" that enhances the person's adaptability in different situations. As such, biculturalism has become the goal in socialising many of the minority and biracial children in the U.S.A. (Herring, 1995). They can now "pick both" instead of the former tendency to have to "choose one" ethnic group.

As seen above, the theoretical literature on biculturalism and biracialism often overlaps, perhaps because of the inconsistent usage of terms like race, ethnicity, and culture described earlier. For example, much of the bicultural literature seems to focus on race, and often examines black/white biracial groups in particular (Brown, 1990; Herring, 1995), although occasionally other biracial combinations such as black and Japanese (Fukuyama, 1999), or white and Japanese (Kich, 1992) are seen in the literature. While admittedly members of any of these groups may also be bicultural, this theoretical overlap highlights another of the major shortcoming in the literature-the failure of investigators to include in their models or empirical populations, people who may have gained a second "culture" that is not racially-different from their first culture-people who are bicultural, but not biracial. 


\section{Acculturation}

Another body of literature worth reviewing is that pertaining to acculturation; that is, the experiences of individuals and groups of people who come in contact with each other, and the resulting changes in cultural attitudes, values and behaviours (Berry, 1998; Berry, Trimble \& Olmedo, 1986). The term has also been used to describe the process by which immigrants acquire, and adapt to, new cultures (LaFromboise et al., 1993).

There are two basic frameworks within the acculturation literature, to explain the acculturation process - a linear bi-polar model and a two-dimensional model (Phinney, 1990). In the former, ethnic identity is seen to exist on a continuum, with strong ethnic (traditional or birth culture) ties on one end, and strong mainstream (or majority culture) ties on the other. To be high in one means to be low in the other; as one gains identification with the mainstream culture, one usually loses one's identification with his/her ethnic origins, and visa versa.

By contrast, the two-dimensional model posits that ethnic identity and mainstream identity are mutually exclusive, and therefore, can run parallel to one another (Berry, 1998; Berry et al., 1986). Within this framework, one can be high or low, in one or both. To illustrate, Berry et al. (1986) conceptualised a framework of the four possible outcomes within this model. If greater emphasis is placed on the mainstream culture, relative to the traditional culture, one is considered to be "assimilated", whereas "separation" results if the person is high in his/her traditional culture but low in the mainstream culture. On the other hand, if one strongly identifies with both the traditional and mainstream cultures simultaneously, they are labelled as "integrated"; if one's identification with both is weak, then they are labelled as "marginal".

(Berry et al., 1986). Following the logic of the former bi-polar model, biculturalism is not an achievable outcome when a person with a unique ethnic background enters a new culture. However, using Berry's two-dimensional model, biculturalism is achievable since the ethnic and mainstream cultures are mutually exclusive, and therefore, can coexist. 
The main limitation of the acculturation research, within the context of this review, is its predominate focus on the acculturation patterns of the group or the individual within his/her group (Lian, 1988). What is missing from the literature is consideration of the acculturation pattern of the individual who does not enter into the new culture within the context of a group or family. For example, what of the adopted child who comes alone into not only a new society, but also a family, which is racially or culturally different? While the literature offers some insight into the acquisition of a second culture, much of it is inadequate to theoretically guide such questions, given the fact that adopted children will enter their "second" culture individually-not as members of families or larger immigrant populations that support the individual through that process. Nor does it offer much information on the developmental stages of secondculture acquisition for children. Yet, in the case of adoption, acculturation will be taking place individually and (at least initially) at the familial level, without anyone from the traditional culture to help transmit that knowledge as happens in most immigrant families (Farver, Narang \& Bhadha, 2002).

Another weakness of the literature is the seemingly implicit assumption that the people being acculturated into the new dominant society will have some experience of the traditional culture from which they have come, and consequently, that the people in question bring culture with them into the new society; whether they then retain it or lose it, and to what degree, are questions central to the acculturation research. This begs the question of whether the original culture can be learned after the fact; if so, the birth or traditional culture would actually become the second culture-a circumstance virtually unconsidered within the acculturation literature.

Additional questions arise when applying the acculturation literature to the adoption context. For example, what about children who were too young to experience the birth culture before they were removed from it? Can we call it "acculturation" or even "integration" (Berry et al., 1986), if one does not have a conscious memory of the birth culture? To further draw on the model by Berry et al. (1986), would the children be 
labelled as "separated" or worse yet, "marginal", given their weak knowledge of the birth culture?

\section{Marginalisation}

The threat of feeling marginalised — of not fitting into either culture-is not unique to the acculturation literature. Many researchers in the field of adoption have speculated that transracially adopted persons have a higher likelihood of experiencing marginalisation. This fear stemmed from the outcomes studies on TRA/ICA, which have provided robust evidence from around the world that adopted children have an overwhelming tendency to ethnically identify with the adoptive parents' dominant (white) culture, more so than with their own ethnic groups (e.g. Brottveit, 1999; Irhammar \& Cederblad, 1999; McRoy \& Zurcher, 1983; Sætersdal \& Dalen, 2000; Westhues \& Cohen, 1998).

This ethnic "mis-identification" led researchers to worry that transracially adopted children would feel a sense of exclusion, or of not belonging to either group (Katz, 1996). To exemplify: a black child raised by white parents, who ethnically selfidentifies as white may experience rejection from the white community due to the fact that physically he presents as black. On the other hand, since his racial group orientation is white, he may be shunned by the black community.

\section{Ethnic socialisation in TRA/ICA}

Fueled in part by fears of adopted persons becoming marginalised between cultures, and repeatedly finding that adopted children continued to ethnically identify with the adoptive parents' culture, practictioners began to encourage adoptive parents to foster in adopted children a birth culture identification. Empirical studies continue to highlight the benefits of parental ethnic socialisation for adopted persons (Alperson, 2001; Huh \& Reid, 2000; Rojewski \& Rojewski, 2001). Yet it seems that many researchers and practitioners are mistaking birth culture socialisation with biculturalisation - and assuming that fostering a birth culture identification equates to a bicultural identity. 
According to Rojewski and Rojewski (2001), when families adopt children from another country, they automatically become multicultural. Fletchman-Smith (1984), on the other hand, has argued that adopting racially-different children does not make the family "racially mixed," even though society may see it that way. The adoptive parents must make a conscious decision about what kind of family they will be; for example, white, mixed, or colour-blind'. Fletchman-Smith further argues that the only viable option for the well-being of the children is a mixed (or bicultural) approach. Yet most families, even if they begin seeking a mixed household, will eventually resort to either a white or colour-blind approach. Fletchman-Smith believes that only families with mixed parentage (i.e. biracial unions) can truly be bicultural. Yet, as reported earlier, even biracial marriages do not necessarily result in a racially-mixed, bicultural atmosphere for the children.

Like the parents in mixed marriages, and immigrant or minority-culture families trying to adapt to a new culture, TRA/ICA parents have the dual role of fostering in their children an ethnic awareness and pride in the birth culture-a role empirically shown to support the child's successful identity development and overall adjustment. At the same time, parents must help their adopted children "fit in" and adapt to the dominant culture (Friedlander et al., 2000)_an outcome that may be just as important for their adjustment and well-being. Nonetheless, the idea that majority-culture identificationthe second ethnicity within the framework of biculturalism—-might be as important to the adopted child's adjustment as birth culture identification has received virtually no research consideration. The Norwegian researcher Brottveit (1999) is one of the few to explicitly argue that adoptees who have a majority-culture identity may be at an advantage. "It can be a sign of strength, not weakness or failure or not coping or false consciousness or what so ever ..." to identify with the dominant culture (p. 128).

\section{Research on biculturalism in TRA/ICA}

According to Westhues and Cohen (1998) in their Canadian research on intercountry adoption, a balance needs to be achieved, that acknowledges a child's ethnic heritage but also permits a sense of belonging within the family and culture. 
Always remembering that your roots are in another cultural reality, but acknowledging that you are now a part of a new culture, would satisfy the child's right to remain connected with their history, but without making them feel that they do not fully belong here ... with their adoptive families. (p. 49)

However, the authors argue that as described, this is not a bicultural identity, as it does not confirm that the adopted child has a sense of understanding and belonging within the two cultures. Nonetheless, they do note that achieving a bicultural identity is possible, although not probable in all cases, "even when parents are committed to facilitating the development of that aspect of their child's identity" (Westhues \& Cohen, 1998, p. 50).

Friedlander and colleagues (2000), in one of the few studies to focus specifically on biculturalism within TRA, conducted exploratory open-ended interviews with eight American families with either Korean or Latin American adopted children. On a question of how members of the family identified themselves, the researchers found that the majority of parents wanted their children to learn about and appreciate diverse groups of people (what would probably be called a mixed approach to parenting), while a smaller percentage focused on minimising group differences, preferring to emphasise shared human qualities and individual self-worth (what would probably be considered a colour-blind approach). The former group, when talking about the family, used terms reflecting diversity, such as "multicultural", and when talking about specific children, the parents used ethnic terms to describe them, based on the children's cultural heritage. Consequently, most of these children described themselves using ethnic terms, supporting the long-held belief that how adoptive parents ethnically identify and describe their children, influences how the children self-identify themselves (e.g. Carstens \& Juliá, 2000; Huh \& Reid, 2000; Irhammar \& Cederblad, 1999; McRoy \& Zurcher, 1983).

However, despite self-labels based on their birth countries, reflecting what Friedlander et al. (2000) believed was their ethnic identities, the researchers concluded that the children had more Euro-American cultural identities, which the authors distinguished as 
"having a sense of shared customs, attitudes, and values with a particular group" (p. 196). They also noted that the children rarely reported feeling pressure to 'choose' one identity over another-a common theme in the biracial development literature discussed earlier (Herring, 1995). Overall, the authors concluded that the study's children showed evidence of holding a dual ethnic or cultural identity, as they seemed to culturally identify with the dominant culture, but also self-describing themselves based on their birth ethnicity. Unfortunately, their method of measuring the dominant culture identity was not made clear (Friedlander et al., 2000)_an issue to be discussed further on.

Scherman and Harré (2008), in their study of Eastern European children adopted into New Zealand, found a similar pattern as Friedlander et al. (2000). Among the 50 adoptees in their study, all of whom were ethnically different but racially similar to their adoptive parents, most described themselves as a combination of their birth culture (Russian or Romanian) and the dominant New Zealand culture. Only 19\% selfidentified themselves as all "Kiwi" (the commonly-used term for New Zealander), even though self-identification with the dominant culture would have been expected for the majority, given the that tendency with children in other TRA studies. A dominantculture identity might also have been expected for a larger number given the fact that the children share the same racial (European) background as the dominant culture. The authors acknowledge, however, that they were not specifically measuring biculturalism, as the study was focussed on the children's birth ethnic identity development within a non-TRA context (Scherman \& Harré, 2008).

In an American study looking at bicultural socialisation in families who had adopted from China, Tessler, Gamache, and Liu (1999) found a strong and generally positive association between parental attitudes towards both American and Chinese cultures. In other words, the authors noted that if parents showed a strong interest in their children knowing about American culture, they also demonstrated a strong desire for their children to know Chinese culture. The discovery of this correlation between birthculture and dominant-culture socialisation is an important contribution to the research on biculturalism in intercountry adoption. However, Tessler et al. acknowledged "it 
would be a mistake to infer that a majority of these children will be truly bi-cultural. Full bi-cultural socialization would require more family foundation in Chinese culture than most adoptive parents realistically can have available to them" (1999, p. xi). This highlights the issue of how achieveable true bicultural competence is for children who come from cultures vastly different from that of the parents raising them. As Tessler et al. (1999) further note, adoptive parents might expose their children to a full range of cultural activities and experiences, however, most will not necessarily rear their children in the full frame of, for instance, the belief system of the birth culture. For example, American adoptive parents may intellectually convey to their children the Eastern concept of collectivism, but will still likely raise their children in the Western tradition of individualism (Tessler et al., 1999).

\section{Summary}

Rotheram and Phinney (1987) questioned whether a bicultural self-identification is possible since, they argued, one cannot simultaneously have two different ethnic selflabels. According to the authors, the most one can hope to achieve is bicultural competence-the ability to function within both cultures. It has also been suggested that a child can be biracial (biologically made up of two different ethnic groups), but still not be bicultural (Herring, 1995). If we accept the definition of cultural competence put forth by LaFromboise et al. (1993) — that one must achieve a sensitivity to the emotional processes, communication and institutional structures, appropriate behaviours, social relations, as well as be knowledgable of the associated beliefs and values associated with the culture-to do so with two different ethnic groups would be a major undertaking.

What conclusions can we draw, therefore, for the adopted child who may be born of one ethnic group while begin raised in the family of a different ethnic group? The importance of adoptive parents providing birth-culture socialisation to enhance adjustment is empirically supported. What remains uncertain is the desireability and/or capacity of adopted persons developing a bicultural identity or even bicultural competence (Thomas \& Tessler, 2007). If we consider biculturalism achieveable-in any context - then the evidence seems strong that it would likely enhance the adoptees' 
adjustment, by reducing the threat of marginalisation; by enabling adoptees to better function within either of the two different cultural contexts; and by allowing them to acknowledge and incorporate into their sense of self, the two cultures that make up who they are as people.

Where to from here? Suggestions for research and practice

In light of the research findings, and noted limitations of the literature, a number of observations and recommendations are offered for researchers and practitioners working with this unique population of adoptive families:

- Empirical consideration is needed to better understand the developmental process by which older international or transracial adoptees, who bring memories of the birth culture with them into their new families, acquire their second culture. The ethnic socialisation literature acknowledges that one's age will play a part in the socialisation process, but offers little else about the actual developmental processes for children or young persons as they acquire their second culture.

- Another major short-coming of the the acculturation literature is the lack of information on second-culture acquisition for persons who entire the new culture as individuals rather than as members of a group, and who, like adopted children, must learn to integrate with not only the wider society, but with a new family as well.

- We also need to gain a better understanding of the acculturation process for children adopted in infancy, wherein the birth or traditional culture becomes the second culture. Is the acculturation process different when the culture of one's birth must be learned, rather than acquired through the experiences of growing up in it? As seen from Tessler et al. (1999), there are numerous subtleties that exist within a culture, which may be difficult (if not impossible) to transmit through parental ethnic socialisation efforts.

- It is also imperative that researchers move beyond the tendency to see ethnicity, culture, and even acculturation, as relating only to minority populations. This shortcoming is further evidenced by the fact that within the ethnic socialisation 
literature, theories of ethnic identity development pertain almost exclusively to people of colour (e.g. Aboud, 1987; Phinney, 1990).

- Another limitation is the confusion between what consitutes biracial and bicultural. Being biracial is not necessarily synonymous with being bicultural. Moreover, to be bicultural does not require one also be biracial. Missing from the literature is a model of biculturalism for people who may have gained a second culture that is not racially-different from their first culture, such as Eastern European children adopted by European families. Scherman \& Harré (2004, 2008) were among the first to investigate ethnic socialisation within same-race intercountry adoptions, yet, many questions remain unanswered. For example, are the issues surrounding biculturalism in intercountry adoption different when the parties involved are not also biracial?

- Improved delineations between what constitutes race, ethnicity and culture are also needed. Steward and Baden (1995) have developed a useful model of ethnic identification that teases out the differences between race and culture in transracial adoption. Their model further distinguishes between the child's culture and race, and the adoptive parents' culture/race. However, like many of the adoption studies described herein, the authors do not detail what constitutes the adoptive parents' majority culture, or how it is measured.

- Finally, we need valid assessment tools that can reliably measure biculturalismnot just birth ethnic identification. As noted earlier, to be culturally competent involves a range of skills including knowledge of, and participation in, cultural behaviours; communication in the language of the group; and negotiating the social mores and structures of the group (LaFromboise et al., 1993; Thomas \& Tessler, 2007; Vonk 2001). As defined, biculturalism, therefore, must incorporate that same range of skills with the birth and majority culture- - the latter being the missing element in most research on biculturalism in adoption (e.g. Brottveit, 1999; Friedlander et al., 2000; Irhammar \& Cederblad, 1999; Scherman \& Harré, 2008; Westhues \& Cohen, 1998). Only Tessler et al. (1999) have explicitly described their process of measuring parental attitudes towards socialisation within the dominant culture, derived from a matched set of birthculture survey items. Given the challenges in even defining culture (Thomas, 
1986), it stands to reason that agreeing on what consitutes any given culture will not be easy. However, the tool created by Tessler et al. (1999) may be a useful model on which to develop additional biculturalism scales for other cultural combinations, as they are needed for the different sending/receiving country adoptive relationships. At a minimum, better effort is needed to assess dominantculture identification, if researchers are going to attempt further studies on biculturalism.

\section{Conclusion}

The popularity of intercountry adoption (currently and in the past) means that there are countless adoptive families with children born of different ethnicities (and/or races) to that of the parents. These families will be faced with a myriad of challenges resulting from the blending of two or more cultural heritages, and will be looking to social workers, clinicians and other practitioners to aid them in raising healthy, happy and well-adjusted children. Toward that end, this paper has sought to critically review and synthesise literature from a somewhat broad but related set of social science fields. The aim was to extrapolate the most essential elements of the literature in order to better understand the often complex experiences of families involved in transracial and intercountry adoptions. The paper also sought to identify the limitations and gaps in the literature so that interested researchers and practitioners might be better able to advance the field through continued empirical research.

\section{Endnotes}

1 The term colour-blind has been used to describe parents who minimise racial or ethnic differences in their children, in favour of non-racial identifiers, such as personality traits or skills when describing their children. See McRoy and Zurcher (1983) for more on this phenomenon in TRA, and Neville, Lilly, Duran, Lee, and Browne (2000) for information on measuring color-blind attitudes generally. 


\section{References}

Aboud, F. (1987). The development of ethnic self-identification and attitudes. In J. S. Phinney \& M. J. Rotheram (Eds.), Children's Ethnic Socialization. Newbury Park, CA: Sage Publications, Inc.

Alperson, M. (2001). Dim Sum, Bagels and Grits: A sourcebook for Multicultural Families. New York: Garrar, Straus and Giroux.

Altstein, H. \& Simon, R. (1991). Intercountry adoption: A Multinational Perspective. New York: Praeger.

American Psychological Association (APA). (2002). Guidelines on multicultural education, training, research, practice, and organizational changes for psychologists. Retrieved 31/12/04, http://www.apa.org/pi/multiculturalguidelines/definitions.html: APA Online.

Berry, J. (1998). Acculturative Stress. In P. B. Organista \& K. M. Chun (Eds.), Readings In ethnic psychology. New York: Routledge.

Berry, J., Trimble, J., \& Olmedo, E. (1986). Assessment of acculturation. In W. Lonner \& J. Berry (Eds.), Field methods in cross-cultural research (pp. 291-324). London: Sage Publications.

Brottveit, Å. (1999). Negotiating ethnic identities: Intercountry transracial adoptee's strategies facing external categorisation. In A. Rygvold, M. Dalen \& B. Sætersdal (Eds.), Mine - yours -ours and theirs: Adoption, changing kinship and family patterns. International Conference at Lysebu, May 6-8 (pp. 125-133). Oslo, Norway: University of Oslo.

Brown, P. M. (1990). Racial identity and social marginality. Child and Adolescent Social Work Journal, 7(4), 319-337.

Caldwell-Colbert, A. T., Fassinger, R. E., Horvat, J., Lamas, J., Mona, L., Mortisugu, J. N., et al. (1998). Enriching the focus on ethnicity and race. APA Monitor, 29(3).

Carstens, C., \& Juliá, M. (2000). Ethnoracial awareness in intercountry adoption: US experiences. International Social Work, 43(1), 61-73.

Cross, W. (1987). A two-factor theory of black identity: Implication for the study of identity development in minority children. In J. S. Phinney \& M. J. Rotheram (Eds.), Children's Ethnic Socialization. Newbury Park, CA: Sage Publications, Inc.

Farver, J., Narang, S. \& Bhadha, B. (2002). East meets west: Ethnic identity, acculturation, and conflict in Asian Indian famlies. Journal of Family Psychology, $16,338-350$.

Fletchman-Smith, B. (1984). Effects of race on adoption and fostering. International Journal of Social Psychiatry, 30, 121-128.

Freundlich, M. (2000). Adoption and Ethics: The Role of Race, Culture, and National Origin in Adoption. Washington DC: Child Welfare League of America. 
Friedlander, M., Larney, L., Skau, M., Hotaling, M., Cutting, M., \& Schwam, M. (2000). Bicultural identification: Experiences of internationally adopted children and their parents. Journal of Counseling Psychology, 47(2), 187-198.

Fukuyama, M. (1999). Personal narrative: Growing up biracial. Journal of Counselling and Development, 77(1), 12-14.

Halsall, P. (1995). Chinese Cultural Studies: Understanding "Culture". Retrieved 31/12/04, http://academic.brooklyn.cuny.edu/core9/phalsall/texts/culture.html.

Helms, J. E. (1990). Black and white racial identity: Theory, research and practice. New York: Greenwood Press.

Herring, R. (1995). Developing biracial ethnic identity: A review of the increasing dilemma. Journal of Multicultural Counseling and Development, 23, 29-38.

Huh, N., \& Reid, W. (2000). Intercountry, transracial adoption and ethnic identity: A Korean example. International Social Work, 43(1), 75-87.

Irhammar, M., \& Cederblad, M. (2000). Outcome of intercounty adoption in Sweden. In P. Selman (Ed.), Intercountry adoption: Developments, trends and perspectives (pp. 143-163). London: British Agencies for Adoption and Fostering.

Katz, I. (1996). The Construction of racial identity in children of mixed parentage. London: Jessica Kingsley Publishers.

Kich, G. (1992). The developmental process of asserting a biracial, bicultural identity. In M. Root (Ed.), Racially Mixed People in America (pp. 304-317). London: Sage Publications Ltd.

LaFromboise, T., Coleman, H., \& Gerton, J. (1993). Psychological impact of biculturalism: Evidence and theory. Psychological Bulletin, 114, 395-412.

Lian, K. (1988). The sociopolitical process of identity formation in an ethnic community: The Chinese in New Zealand. Ethnic and Racial Studies, 11(4), 506532.

McRoy, R., \& Zurcher, L. (1983). Transracial and Inracial Adoptees: The Adolescent Years. Springfield, IL: Charles C. Thomas.

Neville, H. A., Lilly, R. L., Duran, G., Lee, R. M., \& Browne, L. (2000). Construction and initial validation of the color-blind racial attitudes scale (CoBRAS). Journal of Counseling Psychology, 47(1), 59-70.

Phinney, J. S. (1990). Ethnic identity in adolescents and adults: Review of research. Psychological Bulletin, 108, 499-514.

Rojewski, J. W., \& Rojewski, J. L. (2001). Intercountry adoption from China: Examining cultural heritage and other post-adoption issues. Westport, CT: Bergin \& Garvey.

Rosenthal, D. A. (1987). Ethnic identity development in adolescents. In J. S. Phinney \& M. J. Rotheram (Eds.), Children's Ethnic Socialization. Newbury Park, CA: Sage Publications, Inc. 
Rotheram, M. J., \& Phinney, J. S. (1987). Introduction: Definitions and perspectives in the study of Children's Ethnic Socialization. In J. Phinney \& M. J. Rotheram (Eds.), Children's Ethnic Socialization: Pluralism and Development (pp. 10-28). Newbury Park, CA: Sage Publications, Inc.

Sætersdal, B., \& Dalen, M. (2000). Identity formation in a homogeneous country: Norway. In P. Selman (Ed.), Intercountry Adoption: Developments, Trends and Perspectives (pp. 164-180). London: British Agencies for Adoption and Fostering.

Scherman, R., \& Harré, N. (2004). Intercountry adoption of Eastern European children in New Zealand: Parents' attitudes towards the importance of culture. Adoption and Fostering, 28(3), 62-72.

Scherman, R., \& Harré, N. (2008). The ethnic identification of same-race children in intercountry adoption. Adoption Quarterly, 11(1), 45-65.

Selman, P., Moretti, E., \& Brogi, F. (2009). Statistical profile of international adoption in the European Union. Part 1-Chapter 1. International Adoption in the European Union, Final Report from ChildONEurope to the European Parliament. Florence, Italy: Istituto degli Innocenti.

Steward, R., \& Baden, A. (1995). The cultural-racial identity model: Understanding the racial identity and cultural identity development of transracial adoptees. East Lansing, MI: Michigan State University, College of Education.

Tessler, R., Gamache, G. \& Liu, L. (1999). West Meets East: Americans adopt Chinese children. Westport, CT: Bergin \& Garvey.

Thomas, D. (1986). Culture and ethnicity: Maintaining the distinction. Australian Journal of Psychology, 38, 371-380.

Thomas, K. \& Tessler, R. (2007). Bicultural socialization among adoptive families. Journal of Family Issues, 28(9), 1189-1219.

Vonk, M. E. (2001). Cultural competence for transracial adoptive parents. Social Work, 46(3), 246-260.

Westhues, A., \& Cohen, J. (1998). Ethnic and racial identity of internationally adopted adolescents and young adults: Some issues in relation to children's rights. Adoption Quarterly, 1(4), 33-55.

Williams, C. (1999). Claiming a biracial identity: Resisting social construction of race and culture. Journal of Counselling and Development, 77(1), 32-35. 